


\section{About IJMA [last updated October, $\left.1^{\text {st }}, 2021\right]$}

$\checkmark$ International Journal of Medical Arts is the Official Journal of the Damietta Faculty of Medicine, AlAzhar University, Egypt

$\checkmark$ It is an International, Open Access, Double-blind, Peer-reviewed Journal

$\checkmark$ Published four times a year

$\checkmark$ The First Issue was published in July 2019

$\checkmark$ Published under the following license: Creative Commons Attribution-ShareAlike 4.0 International Public License (CC BY-SA 4.0). It had updated from the Creative Commons license [CC BY] in volume 2, Issue 4, October 2020 About IJMA

$\checkmark$ The Egyptian Knowledge Bank hosts the web site of IJMA

$\checkmark$ The Egyptian Knowledge Bank supports IJMA

$\checkmark$ IJMA follows the regulations of the International Committee of Medical Journal Editors

$\checkmark$ IJMA is indexed in the "Directory of Open Access Journals" [15 January 2021].

$\checkmark$ IJMA is indexed in J-Gate [29-6-2021]

$\checkmark$ IJMA is a member of the International Society of Managing and Technical Editors

$\checkmark$ Listed in "Index Copernicus", "Publons", "Academic resource index [ResearchBib]" "Electronics journal library", "Eurasian Scientific Journal Index", "WorldCat" Superstar Journal Database, and "Citefactor"

$\checkmark$ IJMA introduced to the search engine [BASE] through DOAJ

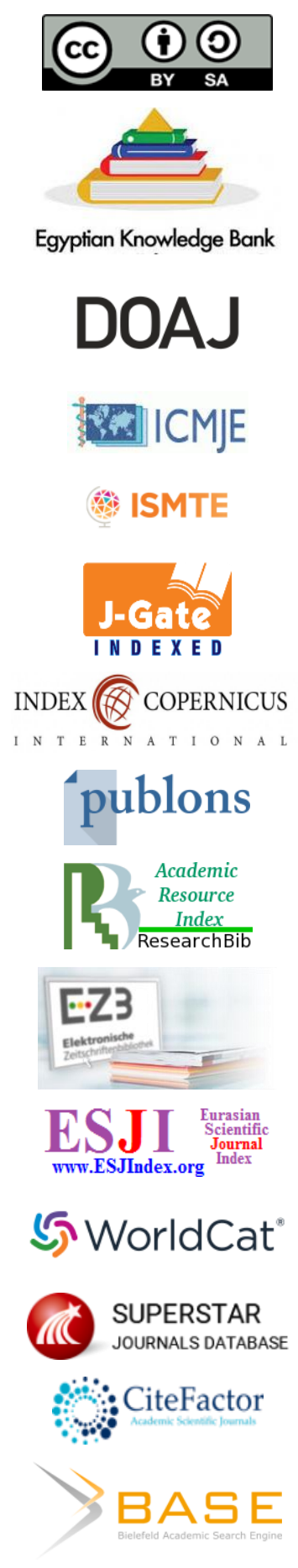




Available online at Journal Website
https://ijma.journals.ekb.eg/
Main subject [Otorhinolaryngology]

Original Article

\title{
Comparative Study between Vitamin D and Placebo in Patients with Nasal Polyps
}

\author{
Ahmed Sobhi Abdelaal [1], Salah Saleh El Hadidi [1], Mohamed Abd-Elkafy Ibrahim [2] \\ 1 Department of Otorhinolaryngology, Faculty of Medicine, Al-Azhar University, Cairo, Egypt \\ 2 Department of Otorhinolaryngology, Mostafa Kamel Military and Alexandria General Military hospital, Egypt \\ Corresponding author: Ahmed Sobhi Abdelaal \\ Email: dr_ahmedsobhi84@yahoo.com
}

Submission date: July 19, 2021; Acceptance date: September 28, 2021

DOI: $10.21608 / I J M A .2021 .86879 .1345$

DOAJ

\section{ABSTRACT}

Background: Chronic rhino-sinusitis with nasal polyps [CRSwNP] is a prevalent disease that has an important influence on patient quality of life. Vitamin D3 [VD3] has been shown to suppress the proliferation of fibroblasts generated from nasal polyps.

Aim of the work: The aim of this work is to evaluate the safety and efficacy of vitamin D3 in decreasing the severity and size of sino-nasal polyps in patients with vitamin D3 insufficiency.

Methods: This study is a prospective cohort study conducted on 46 patients with chronic rhino-sinusitis with nasal polyps with vitamin D3 insufficiency [low levels of vitamin D3 $<30 \mathrm{ng} / \mathrm{ml}$ ]. Included patients were divided into 2 groups, the first group were 22 patients given vitamin D3 [200,000 IU] intramuscular [IM], and the other control group included 20 patients were given placebo in the same manner as the first group. The two groups were assessed before vitamin D3 and placebo supplementation and after 3 months with endoscopic Meltzer grading score and CT scan.

Results: Based on endoscopic Meltzer scores, there was improvement among $68.3 \%$ of vitamin D3 group vs. $20 \%$ of the placebo group; the severity of sino-nasal polyps was observed to be considerably reduced in vitamin D3 group in comparison to placebo group. CT finding reported $40.9 \%$ of vitamin D3 group improved vs. $10 \%$ of placebo group], the improvement of CT was changing of the affected sinuses from complete to partial opacification.

Conclusion: Vitamin D3 has an effective way in lowering the severity of nasal polyps and alleviating their manifestations.

Keywords: Chronic rhino sinusitis; Vitamin D3; Nasal polyps; Disease severity; Endoscopic Meltzer score.

This is an open-access article registered under the Creative Commons, ShareAlike 4.0 International license [CC BY-SA 4.0] [https://creativecommons.org/licenses/by-sa/4.0/legalcode.

Citation: Abdelaal AS, Elhadidy SS, Ibrahim MA. Comparative Study between Vitamin D and Placebo in Patients with Nasal Polyps. IJMA 2021; 3 [4] October-December: 1849-1854 [DOI: 10.21608/JUMA.2021.86879.1345].

* Main subject and any subcategories have been classified according to the research topic 
The vitamin D3 is a lipid soluble vitamin that affects bone and calcium homeostasis as well as T cells and monocytemacrophages [I]. VD3 levels were found to be negatively related to the occurrence of upper respiratory tract infections, and this link was considerably stronger in asthmatics ${ }^{[2]}$.

Vitamin D, has a structure comparable to steroids, has been proposed as an immune-modulatory drug in addition to its well-known pro-skeletal properties. As a result, vitamin $D$ insufficiency has been linked to a number of chronic inflammatory disorders including inflammatory bowel disease, multiple sclerosis, asthma and allergic rhinitis ${ }^{[3]}$. Vitamin D3 derivatives also inhibit nasal polyp-derived fibroblasts from proliferation ${ }^{[4,5] \text {. }}$

Chronic rhino-sinusitis [CRS] is a common disorder marked by mucosal inflammation of the nose and sinuses that lasts longer than three months. It is split into two types: chronic rhino-sinusitis with nasal polyps [CRSwNP] and chronic rhino-sinusitis without nasal polyps [CRSsNP] [6].

Previous research has found that specific types of allergic fungal rhino-sinusitis [AFRS] are more common in people who are more sensitive to VD3 deficiency, adding to the growing body of evidence supporting the role of VD3 in the immunopathology of AFRS and CRSwNP [7]. Furthermore, VD3 deficiency has been linked to increased bone degradation in patients with AFRS and CRSwNP [7-9].

The most common treatment for CRSwNP is topical steroids; nevertheless, the results are occasionally disappointing, and recurrences are common, necessitating surgical intervention ${ }^{[10] .}$

Nonsurgical treatments such as systemic and topical steroids have been proposed to reduce the nasal polyposis recurrence after surgery ${ }^{[11]}$.

It was recently shown that VD3 deficiency is linked to the prevalence of nasal polyps in CRS patients ${ }^{[12,13]}$.

VD3 supplementation has anti-proliferative and antiinflammatory properties, VD3 supplementation may be a lowcost, cost-effective preventative approach in the treatment of patients with AFRS and CRSwNP, either alone or in combination with standard therapy ${ }^{[14]}$.

\section{AIM OF THE WORK}

The purpose of this study was to determine the efficacy of vitamin $D$ therapy in patients with sino-nasal polyps and vitamin $D$ insufficiency in decreasing the severity of disease according to endoscopic Meltzer grading score and CT scan.
Study was conducted on 46 patients with nasal polyps with VD3 insufficiency [low levels of vitamin D3 $<30 \mathrm{ng} / \mathrm{ml}$ ]. Double-blind placebo randomized controlled trial was done at Al-Hussain University Hospital, Mostafa Kamel Military Hospital and Alexandria general Military hospital from January 2021 to June 2021. After enrollment, one patient from the vitamin D3 group and three patients from the control group were not followed up; so, our study finally included 42 patients.

Patients were divided into 2 group, the first group received vitamin D3 [23 patients], and the other group [23 patients] received placebo. Clinical examination was done for both groups before and 3 months after supplementations. All patients had confirmed vitamin $D$ insufficiency [low level below D3 $<30 \mathrm{ng} / \mathrm{ml}$. For the vitamin D3 group, 200,000 IU of vitamin D3 [IM injection] was given as one ampoule that may be repeated after one month if no improvement of vitamin $D$ level. The placebo is given to the patients as IM injection on the same manner as vitamin $D$ with the same container.

Inclusion criteria: Patients over the age of eighteen, having CRSwNP and VD3 serum values $<30 \mathrm{ng} / \mathrm{ml}$ [i.e., VD3 Insufficiency].

Exclusion criteria: Vitamin D3 hypersensitivity, smokers, pregnant or nursing a child, long-term usage of systemic steroids and any recognized systemic problems, such as endocrine, bone, renal, or gastrointestinal diseases.

All patients were examined before and after 3 months of vitamin D3 and placebo intake. Clinical and endoscopic examination with an assessment of the state of the nasal mucosa was conducted by Meltzer endoscopic grading score, both at the start and at the end of the third month after Vitamin D and placebo intake. Follow-up with CT scan was made before and after 3 months of vitamin D3 and placebo administration. Comparison between the two groups was done by Meltzer endoscopic grading score and CT scans before and after 3 months of vitamin D3 and placebo intake.

\section{Ethical considerations}

Before beginning this study, approval was done the AlAzhar faculty of medicine's ethics committee to every patient. Signed informed written consent was taken from the patients after providing detailed information regarding the study.

\section{Statistical analysis}

Statistical package for social science [SPSS] was used to code, enter, and process the data [version 24]. The descriptive statistics employed were mean, standard deviation, frequency, and percentage. The association was 
tested using the Chi-Square test [ $\left.\mathrm{X}^{2}\right]$. Regarding independent samples, the statistical significance of the difference between two populations was determined using the Student's t-test. For all tests, non-significance was identified if the $P$ value is $>$ 0.05 ; significant if the $P$ value is $<0.05$.

\section{RESULTS}

The mean age in vitamin D3 group was $39.32 \pm 10.48$ and in the control group was $44.05 \pm 5.11$. Regarding sex, vitamin D3 group included 9 females [40.9\%] and 13 males [59.1\%], while the placebo group included 9 females [45\%] and 11 males [55.0\%]. There was no statistically significant difference between both groups regarding age and sex [Table 1].

There was no statistically significant difference in the distribution of chronic sinusitis with nasal polyps between vitamin D3 group and placebo group according to endoscopic Meltzer grading score finding or CT finding before vitamin $D$ and placebo administration [Table 2].
After 3 months, there was partial improvement in patients given vitamin D3 as there was partial improvement of five out of six patients with massive nasal polyposis [grade 4] whom changed into grade [3]. Five out of 6 patients with extensive nasal polyposis beyond the middle meatus [grade 3] whom changed into grade [2]. Three out of 5 patients with polyps blocking the middle meatus [grade 2] partially improved into grade [1] and four out of five patients with small polyps in the middle meatus were improved into grade [0]. In the placebo group, only one from six patients was partially improved from grade [4] to grade [3], only one patient from 6 patients with grade [3] partially improved grade [2], one patient from five patients with grade [2] partially improved grade [1], and one patient from five patients with grade [1] was improved to grade [0]. CT of the studied patients showed partial improvement of nine patients from 22 patients, while the other control group showed only 2 patients from 20 patients with partial improvement as shown in figures [1, 2] and table [3].

Table [1]: Comparison between vitamin D3 group and placebo group regarding age and sex

\begin{tabular}{|l|c|c|c|c|c|}
\hline \multicolumn{2}{|c|}{} & Vitamin D3 group & Placebo group & Test & P. value \\
\hline Age & Mean \pm SD & $39.32 \pm 10.48$ & $44.05 \pm 5.11$ & 1.829 & 0.075 \\
\hline Sex & Female & $9[40.9 \%]$ & $9[45.0 \%]$ & \multirow{2}{*}{0.072} & \multirow{2}{*}{0.789} \\
\hline
\end{tabular}

Table [2]: Comparison between vitamin D3 and placebo groups regarding endoscopic Meltzer score and CT finding before treatment

\begin{tabular}{|c|c|c|c|c|c|}
\hline & & Vitamin D3 group & Placebo group & $\mathrm{X}^{2}$ & $P$ value \\
\hline Endoscopic & Massive nasal polyposis (grade 4) & $6[27.3 \%]$ & $6[30.0 \%]$ & \multirow{4}{*}{0.107} & \multirow{4}{*}{0.991} \\
\hline \multirow[t]{3}{*}{$\begin{array}{l}\text { Meltzer score } \\
\text { finding }\end{array}$} & Polyp extending beyond the middle meatus & 6 [27.3\%] & 5 [25.0\%] & & \\
\hline & Polyps blocking the middle meatus (grade 2) & 5 [22.7\%] & 4 [20.0\%] & & \\
\hline & Small polyp in middle meatus (grade 1 ) & $5[22.7 \%]$ & $5[25.0 \%]$ & & \\
\hline \multirow[t]{2}{*}{ CT finding } & $\begin{array}{l}\text { Complete opacification of ethmoidal, } \\
\text { maxillary frontal and sohenoidal sinuses }\end{array}$ & 17 [77.3\%] & $15[75.0 \%]$ & \multirow{2}{*}{0.03} & \multirow{2}{*}{0.86} \\
\hline & $\begin{array}{l}\text { Complete opacification of maxillary and } \\
\text { ethmoidal sinuses }\end{array}$ & $5[22.7 \%]$ & $5[25.0 \%]$ & & \\
\hline
\end{tabular}

Table [3]: Comparison between vitamin D3 and placebo groups regarding studied outcomes after 3 months of supplementation

\begin{tabular}{|c|c|c|c|c|c|}
\hline \multicolumn{3}{|c|}{ Variables } & Vitamin D3 group & Placebo group & P value \\
\hline $\begin{array}{l}\text { Endoscopic } \\
\text { Meltzer score }\end{array}$ & $\begin{array}{l}\text { Massive nasal polyposis } \\
\text { (grade 4) }\end{array}$ & $\begin{array}{c}\text { Improved } \\
\text { Not improved }\end{array}$ & $\begin{array}{c}5[22.7 \%] \\
1[4.5 \%]\end{array}$ & $\begin{array}{c}1[5.0 \%] \\
5[25.0 \%]\end{array}$ & 0.08 \\
\hline & $\begin{array}{l}\text { Polyp extending beyond the } \\
\text { middle meatus (grade } 3 \text { ) }\end{array}$ & $\begin{array}{c}\text { Improved } \\
\text { Not improved }\end{array}$ & $\begin{array}{c}5[22.7 \%] \\
1[4.3 \%]\end{array}$ & $\begin{array}{c}1[5.0 \%] \\
5[25.0 \%]\end{array}$ & 0.08 \\
\hline & $\begin{array}{l}\text { Polyps blocking the middle } \\
\text { meatus (grade } 2 \text { ) }\end{array}$ & $\begin{array}{l}\text { Improved } \\
\text { Not improved }\end{array}$ & $\begin{array}{l}3[13.6 \%] \\
2[9.1 \%]\end{array}$ & $\begin{array}{c}1[5.0 \%] \\
4[20.0 \%]\end{array}$ & 0.52 \\
\hline & $\begin{array}{l}\text { Small polyp in middle } \\
\text { meatus (grade 1) }\end{array}$ & $\begin{array}{l}\text { Improved } \\
\text { Not improved }\end{array}$ & $\begin{array}{c}4[18.2 \%] \\
1[4.3 \%]\end{array}$ & $\begin{array}{l}1[5.0 \%] \\
4[20.0 \%]\end{array}$ & 0.2 \\
\hline \multicolumn{2}{|c|}{ Endoscopic Meltzer grading score } & $\begin{array}{l}\text { Improved } \\
\text { Not improved }\end{array}$ & $\begin{array}{c}17[77.3 \%] \\
5[22.7 \%]\end{array}$ & $\begin{array}{c}4[20.0 \%] \\
16[80.0 \%]\end{array}$ & $<0.001^{*}$ \\
\hline \multicolumn{2}{|l|}{ C T finding } & $\begin{array}{l}\text { Improved } \\
\text { Not improved }\end{array}$ & $\begin{array}{c}9[40.9 \%] \\
13[59.1 \%]\end{array}$ & $\begin{array}{l}2[10 \%] \\
18[90 \%]\end{array}$ & 0.035 \\
\hline
\end{tabular}




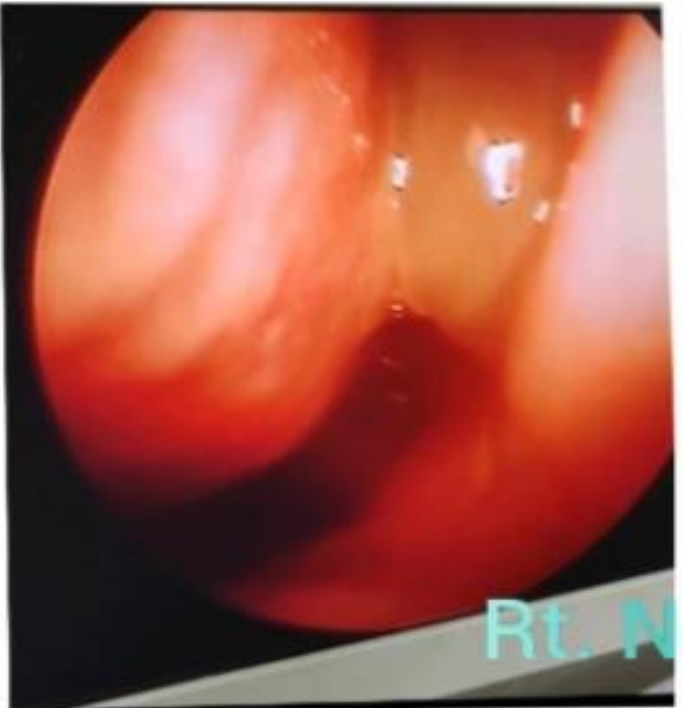

Beginning of the study

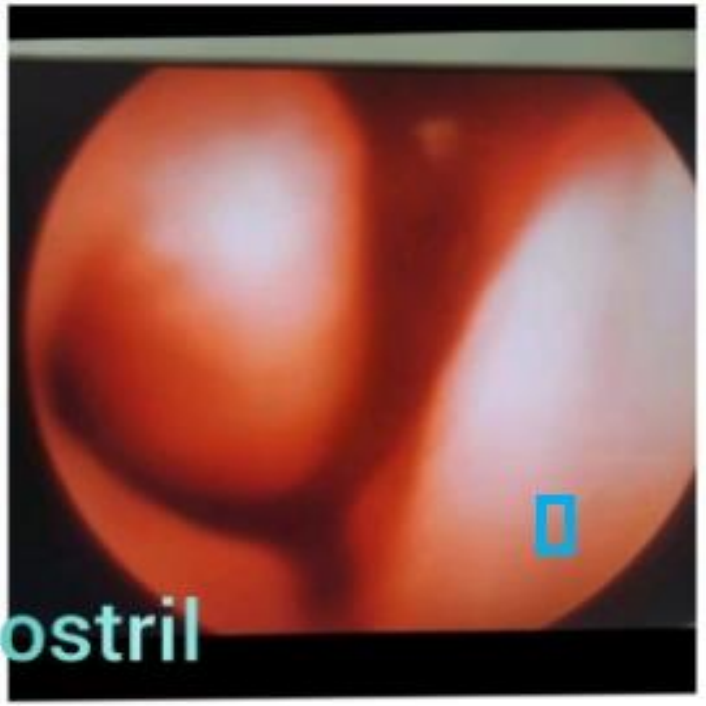

3rd month after vitamin D administration

Figure [1]: Endoscopic finding of female patient 31 years with chronic sinusitis with nasal polyps blocking the middle meatus before and after 3 months of vitamin D3 supplementation [grade 3 changed to grade 1 as the polyps were decreased in size].

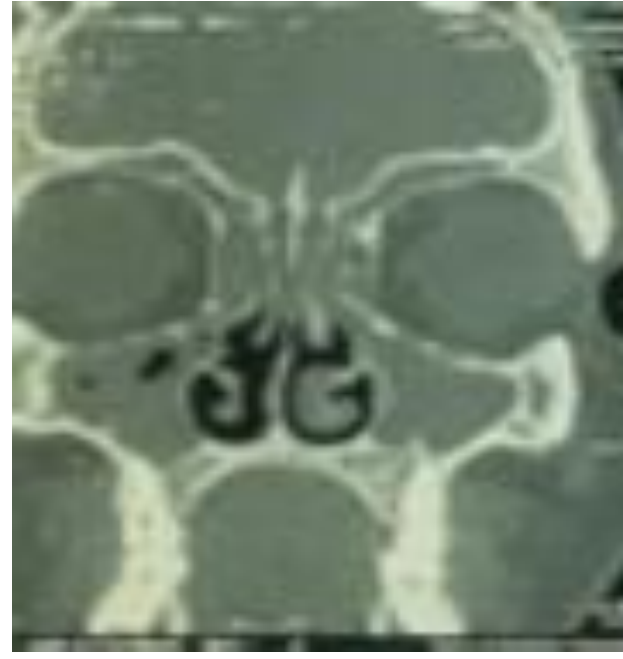

Before vitamin D3 supplementation

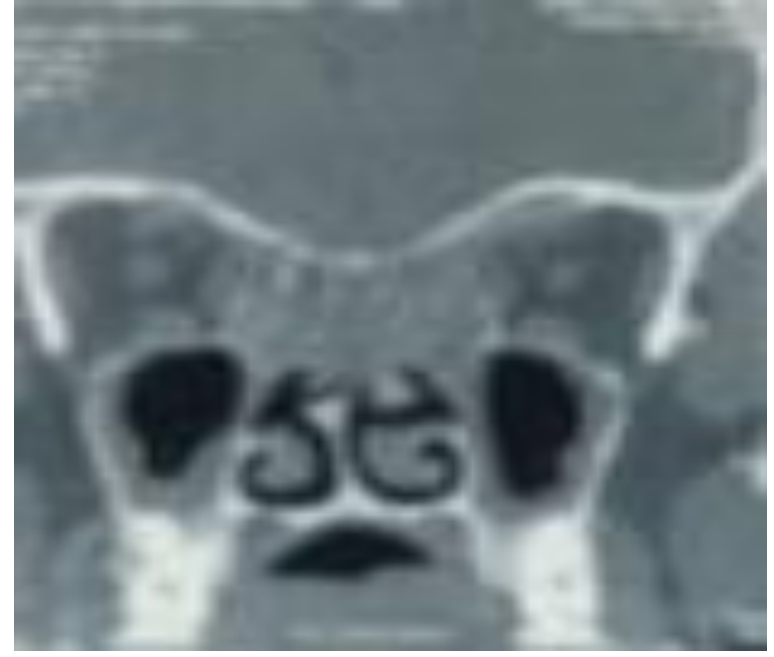

After vitamin D3 supplementation

Figure [2]: CT of male patient 43 years presented with massive nasal polyposis grade (4). After 3 months of vitamin D supplementation, it showed partial improvement changing from complete opacification of maxillary sinus to partial opacification with decreasing the severity of nasal manifestation

\section{DISCUSSION}

The most successful treatment for rhinosinonasal polyposis is reported to be endoscopic sinus surgery. However, it is not possible to remove all the microscopic inflammatory tissues. Thus, the residual inflammatory tissues in the nose and sinuses may contribute to recurring of nasal polyps [15]. As a result, a number of nonsurgical therapies have been recommended to reduce polyposis recurrence after surgery, including systemic and topical steroids [11].

It was recently reported that deficiency of vitamin D3 is linked to the prevalence of the sinonasal polyps in patients with CRS [12, 13]. Hashemian et al. ${ }^{[15]}$ reported the safety and efficacy of vitamin D3 administration on recurrence of nasal polyps following endoscopic nasal surgery that is correlated with the results of our study denoted by the partial improvement of 17 patients with CRSwNP from 22 patients according to endoscopic Meltzer grading score and CT findings within 3 months of vitamin D3 supplementation. The findings of our study were consistent with other several studies looking at the effects of administration of vitamin D3 on CRSwNP. 
Much research had looked into possible links between VD3 levels in the blood and symptoms in patients with AFRS and CRSwNP. Mostafa et al. ${ }^{[14]}$ for example, examined serum levels of VD3 in 74 patients with CRS, AFRS, and CRSwNP. VD3 levels in patients with AFRS were found to be considerably lower than the control group in the aforementioned study. As a result, based on the findings of this investigation, the study concluded that VD3 could be a cheap and cost-effective preventative approach in the treatment of AFRS and CRSwNP, either alone or in combination with standard therapy.

Schlosser et al. [16] looked at the impact of vitamin D3 insufficiency on clinical manifestations in patients with CRSwNP in a retrospective research; according to the findings of their study, lower levels of vitamin D3 were reported in 55 percent. Low levels of vitamin D3 were also linked to more severe illness of the nasal mucosa in C T images that is consistent with the current study's results.

In a separate investigation, Carrol and Schlosser [17] examined 15 individuals with CRSwNP and found that vitamin $D$ insufficiency is associated with increased the proliferation of fibroblasts of the human sinus. The fibroblast proliferation index was found to be significantly lower in individuals with CRSwNP who were given calcitriol tablets $[P=0.01]$, but not in the control group.

Faruk et al. ${ }^{[18]}$ investigated the efficacy of a large -dose [4000 IU/day] and a low-dose [1000 IU/day] vitamin D3 in lowering the size of nasal polyps and alleviating illness symptoms. The group that got high-dose vitamin D3 demonstrated a considerable reduction in all visual analogue scale symptoms [VAS] and endoscopic scores, which was almost identical to the results of the current investigation. As a result, it was established that high-dose vitamin D3 administration is likely to be useful in alleviating nasal polyposis symptoms and repairing the nasal mucosa following surgery.

In CRSwNP patients, VD3 and basic fibroblast growth factor have a significant negative relationship according to Sansoni et al. ${ }^{[19]}$ as they conclude that VD3 is a fibroblast growth factor regulator in CRSwNP.

All these results coincide with our results that are after 3 months of VD3 supplementation there was improvement of 17 patients with CRSwNP from 22 cases. The 17 patients had variant grades according to endoscopic Meltzer grading score. The cases improved to the better previous graded endoscopic grading score [decreasing the severity of the nasal polyposis]. In the control placebo group, only 4 patients improved from 20 patients with statistical significant different from the study group with VD3 supplementation according to endoscopic Meltzer grading score.
CONCLUSION

In conclusion, the current study's findings demonstrated the efficacy of vitamin D3 supplementation in decreasing the severity of nasal polyps in patients had chronic sinusitis with nasal polyps.

Financial and non-financial relationships and Activities of Interest

None

\section{REFERENCES}

I. Hackstein H, Thomson AW. Dendritic cells: emerging pharmacological targets of immunosuppressive drugs. Nat Rev Immunol. 2004 Jan;4(1):24-34. DOI: 10.1038/ nri1256.

2. Ginde AA, Mansbach JM, Camargo CA Jr. Association between serum 25-hydroxyvitamin $D$ level and upper respiratory tract infection in the Third National Health and Nutrition Examination Survey. Arch Intern Med. 2009 23; 169(4):384-90. DOI: 10.1001/archinternmed.2008.560.

3. Beloyartseva M, Mithal A, Kaur P, Kalra S, Baruah MP, Mukhopadhyay S, Bantwal G, Bandgar TR. Widespread vitamin $D$ deficiency among Indian health care professionals. Arch Osteoporos. 2012;7:187-92. DOl: 10.1007/s11657-012-0096-X.

4. Rostkowska-Nadolska B, Fraczek M, Gawron W, Latocha $M$. Influence of vitamin $D(3)$ analogues in combination with budesonid $\mathrm{R}$ on proliferation of nasal polyp fibroblasts. Acta Biochim Pol. 2009;56(2):235-42. DOI:10.18388/ABP.2009_2454.

5. Fraczek $M$, Rostkowska-Nadolska $B$, Kusmierz $D$, Zielinska A, Rok J, Sliupkas-Dyrda E, et al. Vitamin D analogs decrease in vitro secretion of RANTES and enhance the effect of budesonide. Adv Med Sci. 2012;57(2):290-5. DOI: 10.2478/v10039-012-0043-5.

6. Hashemian F, Baghbanian N, Majd Z, Rouini MR, Jahanshahi J, Hashemian F. The effect of thyme honey nasal spray on chronic rhinosinusitis: a double-blind randomized controlled clinical trial. Eur Arch Otorhinolaryngol. 2015 Jun;272(6):1429-35. DOI: 10.1007/s00405-014-3233-x.

7. Mulligan JK, Bleier BS, O'Connell $B$, Mulligan RM, Wagner C, Schlosser RJ. Vitamin D3 correlates inversely with systemic dendritic cell numbers and bone erosion in chronic rhinosinusitis with nasal polyps and allergic fungal rhinosinusitis. Clin Exp Immunol. 2011 
Jun;164(3):312-20. DOI: 10.1111/j.1365-2249.2011. 04325.x.

8. Hansdottir S, Monick MM. Vitamin D effects on lung immunity and respiratory diseases. Vitam Horm. 2011;86:217-37. DOI: 10.1016/B978-0-12-386960-9. 00009-5.

9. Wise SK, Rogers GA, Ghegan MD, Harvey RJ, Delgaudio $\mathrm{JM}$, Schlosser RJ. Radiologic staging system for allergic fungal rhinosinusitis (AFRS). Otolaryngol Head Neck Surg.;140(5):735-40. DOI: 10.1016/j.otohns.2008.12.053.

10. Mullol J, Roca-Ferrer J, Alobid I, Pujols L, Valero A, Xaubet A, Bernal-Sprekelsen M, Picado C. Effect of desloratadine on epithelial cell granulocyte-macrophage colony-stimulating factor secretion and eosinophil survival. Clin Exp Allergy. 2006 Jan;36(1):52-8. DOI: 10.1111/j.1365-2222.2005.02403.x.

11. Fokkens WJ, Lund VJ, Mullol J, Bachert C, Alobid I, Baroody F, et al. EPOS 2012: European position paper on rhinosinusitis and nasal polyps 2012. A summary for otorhinolaryngologists. Rhinology. 2012 Mar;50[1]:1-12. DOI: 10.4193/Rhino12.000.

12. Konstantinidis I, Fotoulaki M, lakovou I, Chatziavramidis A, Mpalaris V, Shobat K, Markou K. Vitamin $D_{3}$ deficiency and its association with nasal polyposis in patients with cystic fibrosis and patients with chronic rhinosinusitis. Am J Rhinol Allergy. 2017 Nov 1;31[6]:395-400. DOI: 10.2500/ajra.2017.31.4484.

13. Faghih Habibi A, Gerami H, Banan R, Kazemnezhad Leily E, Khoshkhat P, Alaie Alamouti H, Nemati S. Serum 25-Hydroxy Vitamin D in Chronic Rhinosinusitis with and Without Nasal Polyposis: A Case-Control Study. Iran J Otorhinolaryngol. 2019 Jan;31(102):19-24. PMID: 30783595
14. Mostafa Bel-D, Taha MS, Abdel Hamid T, Omran A, Lotfi $N$. Evaluation of vitamin $D$ levels in allergic fungal sinusitis, chronic rhinosinusitis, and chronic rhinosinusitis with polyposis. Int Forum Allergy Rhinol. 2016 Feb;6[2]:185-90. DOI: 10.1002/alr.21585.

15. Hashemian F, Sadegh S, Jahanshahi J, Seif Rabiei MA, Hashemian F. Effects of Vitamin D Supplementation on Recurrence of Nasal Polyposis after Endoscopic Sinus Surgery. Iran J Otorhinolaryngol. 2020 Jan;32[108]:2128. DOI: 10.22038/ijorl.2019.37766.2241

16. Schlosser RJ, Soler ZM, Schmedes GW, Storck K, Mulligan JK. Impact of vitamin $D$ deficiency upon clinical presentation in nasal polyposis. Int Forum Allergy Rhinol. 2014 Mar;4[3]:196-9. DOI: 10.1002/alr.21274.

17. Carroll WW, Schlosser RJ, O'Connell BP, Soler ZM, Mulligan JK. Vitamin D deficiency is associated with increased human sinonasal fibroblast proliferation in chronic rhinosinusitis with nasal polyps. Int Forum Allergy Rhinol. 2016 Jun;6[6]:605-10. DOI: 10.1002/alr.21704.

18. Faruk EM, Yousef MM, Mohamed T. Does vitamin D have protective effect on human nasal polyposis: histological and immunohistochemical study. J Histol Histopathol. 2014;1:2. DOI: 10.7243/2055-091X-1-2.

19. Sansoni ER, Sautter NB, Mace JC, Smith TL, Yawn JR, Lawrence LA, et al. Vitamin D3 as a novel regulator of basic fibroblast growth factor in chronic rhinosinusitis with nasal polyposis. Int Forum Allergy Rhinol. 2015 Mar;5[3]:191-6. DOI: 10.1002/alr.21474. 


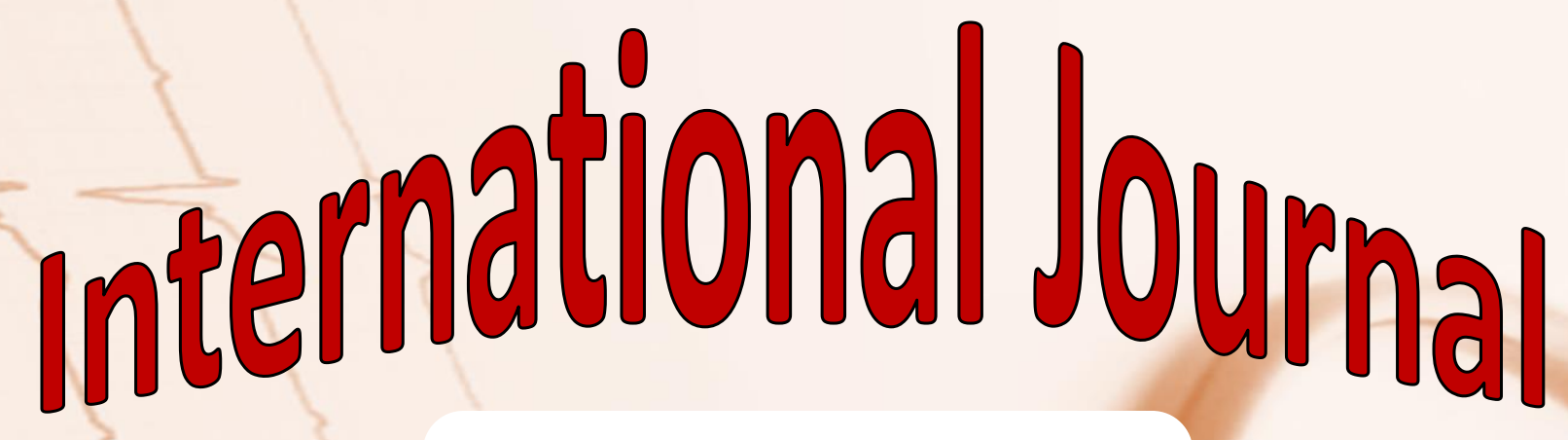

https://ijma.journals.ekb.eg/ Print ISSN: 2636-4174 Online ISSN: 2682-3780

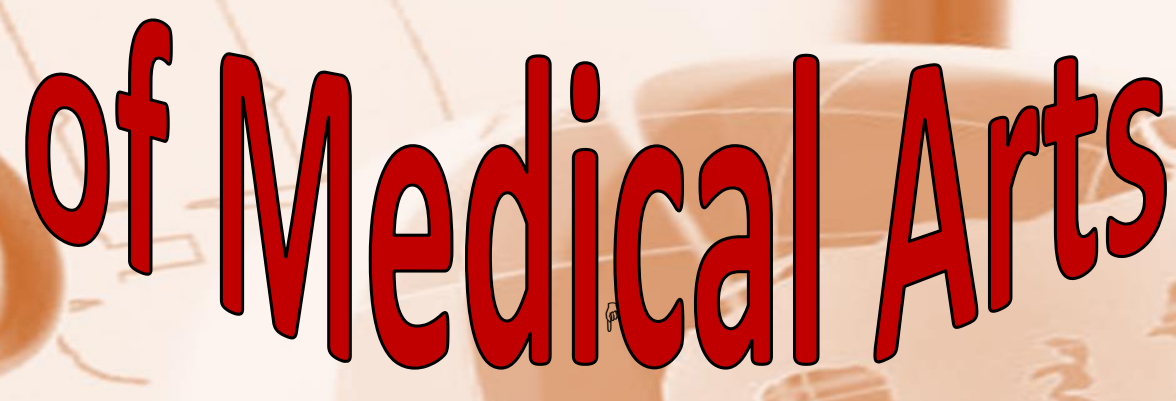

